\title{
RESEARCH METHOD OF REDUCING POLARIZATION LAYER AT ULTRAFILTRATION OF COTTAGE CHEESE WHEY
}

\author{
Gregoriy Deynichenko ${ }^{1}$ \\ deinychenkogv@ukr.net \\ Vasyl Guzenko \\ zasada.avas.3@gmail.com \\ Dmytro Dmytrevskyi ${ }^{1}$ \\ dmitrevskyidv@gmail.com \\ Vitalii Chervonyi ${ }^{1}$ \\ chervonyi.v@gmail.com \\ Aleksandr Omelchenko \\ PhD, Associate Professor ${ }^{2}$ \\ omelchenko@donnuet.edu.ua \\ Dmytro Horielkov ${ }^{2}$ \\ gorelkov.dmv@gmail.com \\ Olga Melnik \\ PhD, Associate Professor \\ melnikolgaev@gmail.com \\ Olha Korolenko \\ PhD, Associate Professor ${ }^{3}$ \\ korolenko.ob@gmail.com \\ ${ }^{1}$ Department of Processes and Equipment Food and Hospitality-Restaurant Industry \\ named after M. Belaeva \\ Kharkiv State University of Food Technology and Trade \\ 333 Klochkivska str., Kharkiv, Ukraine, 61051 \\ ${ }^{2}$ Department of General Engineering Disciplines and Equipment \\ Mykhailo Tugan-Baranovsky Donetsk National University of Economics and Trade \\ 16 Tramvaina str., Kryvyi Rih, Ukraine, 50005 \\ ${ }^{3}$ Department of Power Supply and Energy Management \\ Kryvyi Rih National University \\ 11 Vitaliya Matusevycha str., Kryvyi Rih, Ukraine, 50027
}

\begin{abstract}
The aim of the work is to study the process of membrane concentration of cottage cheese whey, using the bubbling method for decreasing polarization layer formation at the UF-membrane surface.

A description of the experimental set and processing method for research results of using the method of fighting against a polarization layer in the process of membrane concentration of protein-carbohydrate milk raw materials are presented. Results of the experimental studies as to using the bubbling method for decreasing polarization layer formation in the process of membrane concentration of cottage cheese whey and its influence on concentration membranes productivity are given. Mathematical models, based on regression equations of factorial experiment with using the method of bubbling separated liquid above the membrane surface for choosing technological parameters of process of membrane concentration of cottage cheese whey, have been constructed. Graphic dependencies of the productivity of ultrafiltration polymer membranes of PAN type depending on initial pressure and temperature parameters of the process of membrane concentration are presented. Rational parameters of membrane concentration of cottage cheese whey using the method of bubbling initial raw materials by gas bubbles, directly close to the concentration membrane surface have been determined. Such parameters are: pressure - 0.4 ...0.5 MPa, temperature of skimmed milk $-40 \ldots 50{ }^{\circ} \mathrm{C}$, skimmed
\end{abstract}


milk bubbling frequency $-0.10 \ldots 0.15 \mathrm{~min}^{-1}$, bubbling pressure must be $0.56 \ldots 0.58 \mathrm{MPa}$. The expedience of using the new-method of gel-layer elimination has been established according to research results.

Keywords: cottage cheese whey, membrane concentration, polarization layer, concentration membranes, bubbling.

DOI: $10.21303 / 2504-5695.2020 .001375$

\section{Introduction}

The use of membrane concentration methods (in particular, ultrafiltration) at processing such skimmed milk-protein raw material as cottage cheese whey opens essential possibilities for milk processing enterprises, both in creating new technologies, increasing production profitability and providing ecological safety $[1,2]$.

The use of ultrafiltration at milk raw materials concentration may be realized much cheaper than, for example, by evaporation or freezing. It is explained by an increase of resource saving at getting new products without losing labile components and taste worsening that often takes place at concentrating by thermal processing methods. At that ecological safety increases at the expanse of a minimal amount of waste that undoubtedly has a positive influence on the environment.

The aim of the work is to study the process of membrane concentration of cottage cheese whey using the bubbling method for decreasing polarization layer formation at the UF-membrane surface.

The following tasks were set for attaining this aim:

- to give a characteristic to modern ways of decreasing the polarization layer on the UF-membrane surface;

- to determine factors, influencing the process of membrane concentration of cottage cheese whey using the bubbling method;

- based on research results, to determine rational parameters of membrane concentration of cottage cheese whey.

A retaining role in the development of membrane processing methods of protein-carbohydrate milk raw materials is played by low specific productivity of UF-membranes, conditioned by specific properties of high-molecular substances of protein-carbohydrate raw materials [3, 4]. At that the wide introduction of membrane processes is interfered by the decrease of UF-membranes penetrability in the process of separation, which main cause is considered as residue layer formation on the UF-membrane surface - polarization layer [5, 6]. For decreasing polarization layer formation, it is necessary to provide a device in the developed membrane equipment construction that would turbulize the flow of the separated high-molecular liquid polydisperse system [7].

Hydromechanical ways of decreasing a speed of concentration polarization layer formation must be considered as most effective ones [8]. Ways and devices of hydromechanical decrease of polarization layer formation on membranes surface may be studied in works $[9,10]$. The use of the bubbling process of the separated system flow looks promising among the spectrum of existing hydromechanical ones. The expected result of using this process provides a necessity of studying working parameters of cottage cheese whey bubbling and its influence on the quantitative characteristic of the membrane concentration process.

\section{Materials and methods for studying the process of membrane concentration of cottage cheese whey as a method for decreasing the polarization layer}

For intensifying the process of membrane concentration of cottage cheese whey as a method for decreasing a speed of polarization layer formation, there was offered to bubble the processed food high-molecular liquid by air or inert gas bubbles, directly closely to the surface of semi-penetrable UF-membranes. A device for bubbling as torus has two surfaces that distribute condensed air or inert gas within the initial raw material (cottage cheese whey). The process of membrane condensation is realized at the expanse of the total influence of bubbling pressure, turbulization of flows of the processed liquid and hydraulic stroke on the UF-membrane surface on the polarization layer, formed on the UF-membrane surface. At that it is provided to increase the productivity of UF-membranes as a result of decreasing a speed of the polarization layer formation on its surface [11]. 
For getting influence dependencies of the method of vibration mixing on the productivity of UF-membranes, all experiments were conducted in fivefold repetition. The obtained data were processed by the method of mathematical statistics and correlation analysis with using the table processor Excel 2007, and also the problem-oriented package Mathcad 15. Differences were considered as statistically significant at the reliability $A=0.95$.

\section{1. Experimental procedures-}

The scheme of the membrane experimental set with the device for bubbling is presented on Fig. 1, the outlook - on Fig. 2.

Filtering module 1 of stainless steel with internal volume 51 stands on the base. Flanges are welded to the upper and lower module bases, upper 3 and lower 4 covers are fixed to them. Hermeticity of their fixation is provided by rubber gaskets 15 . UF-membrane 16 is fixed on the lower cover with an orifice for permeate outflow. Manometer 2 for controlling the process pressure and thermocouple 18, connected with potentiometer 17 CSP-4 (SE "Lvivdevice", Ukraine), are placed on the upper cover. There is also placed valve 9 for delivering and discharging the pressure from compressor 10 [12].

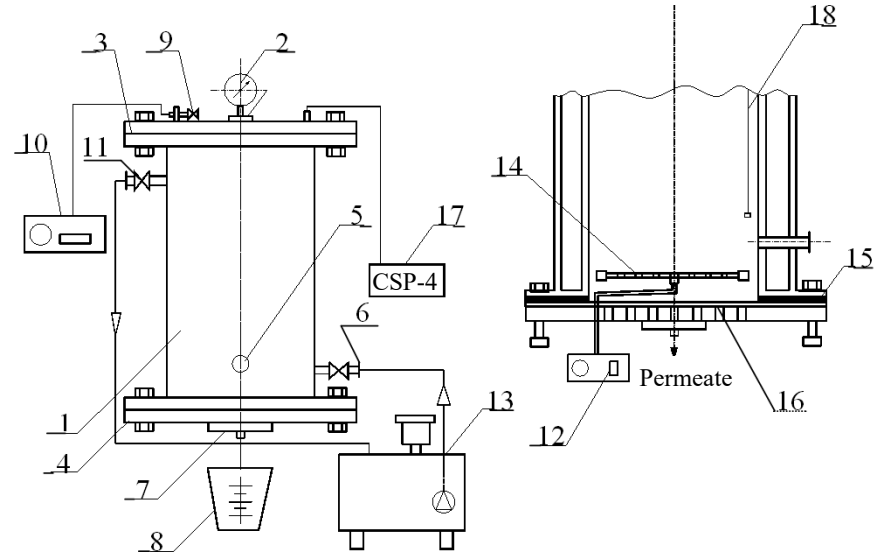

Fig. 1. Principal scheme of the membrane experimental set, based on the membrane module with the bubbling device: 1 - body; 2 - manometer; 3 - upper cover; 4 -lower cover;

5 - valve for removing formed concentrate; 6 - nozzle for coolant input; 7 -valve for removing filtrate; 8 - vessel for permeate collection; 9 - valve for delivering and discharging pressure; 10 - compressor for pressure pumping; 11 - nozzle for coolant output; 12 - compressor for bubbling; 13 - ultrathermostat (UT-15); 14 - device for bubbling; 15 - tightening gasket; 16 - ultrafiltration membrane; 17 - potentiometer CSP-4; 18 - thermocouple

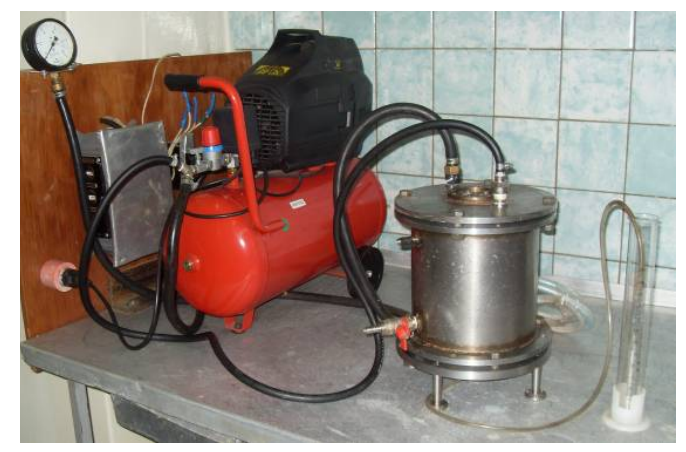

Fig. 2. Outlook of the experimental set

Bubbling device (bubbler) 14, connected with bubbling compressor 12, is placed within the working chamber of the module. The filtering module is equipped with a water jacket, water temperature in it is regulated by ultrathermostat UT-15 (Odessa experimental plant of laborato- 
ry medical technique, Ukraine) 13 though nozzles of coolant input 6 and output 11 . Valve 5 for removing UF-concentrate of milk raw materials is in the lower part of the module. Permeate is removed by connecting pipe 7 from the module to container 8 . The summary working membrane surface is $0,024 \mathrm{~m}^{2}$.

The work of the ultrafiltration laboratory set is realized by the following way. The working chamber of the filtering membrane module is filled by separated raw materials, the necessary pressure is created by the compressor, and the ultrafiltration process is realized. For studying the bubbling influence on the process of ultrafiltration separation of the food liquid, the bubbling compressor that creates turbulization of the system near the semi-penetrable membrane surface by the bubbling device is switched on. In the process of ultrafultration permeate passes through membrane pores, is removed from the filtering module by the connecting pipe and collected in the container. Concentrate of the separated liquid after reaching the necessary value of the concentration factor is removed from the filtering module by the valve.

This work studies ultrafiltration membranes of PAN type: PAN-50 and PAN-100. PAN type membranes are ultrafiltration semi-permeable ones, produced, based on acrylonitrile solo polymers with pore sizes 50 and $100 \mathrm{~nm}$ respectively.

\section{Mathematic modeling of the process of membrane concentration of skimmed milk}

For determining technological parameters of the process of membrane concentration of skimmed milk, the mathematical model by the method of experiment planning was used. Regression equations (1), (2), obtained as a result of modeling changing parameters of membrane concentration of skimmed milk, favor more detail study of phenomena, taking place on the membrane surface, based on acrlylonitrile solo polymers (PAN) at ultrafiltration of skimmed milk raw materials [13].

The membrane productivity at membrane concentration of cottage cheese whey in usual regime:

$$
\begin{gathered}
\mathrm{G}_{\mathrm{c}}=2,078+0,136 t+31,969 P-1,442 \tau-5,202 \cdot 10^{-4} t^{2}- \\
-39,575 P^{2}+0,223 \tau^{2}-3,333 \cdot 10^{-3} t \cdot P-0,014 t \cdot \tau+1,467 P \cdot \tau,
\end{gathered}
$$

where $t$ - temperature of UF-concentration, ${ }^{\circ} \mathrm{C} ; P$ - filtration pressure, $\mathrm{MPa} ; \tau$ - duration of the membrane concentration process.

The membrane productivity at membrane concentration of cottage cheese whey using the bubbling method:

$$
\begin{gathered}
\mathrm{G}_{\mathrm{c}}^{\mathrm{b}}=-36,803+0,069 t+42,708 P+116,559 P_{l}+24,698 n_{b}+3,323 \cdot 10^{-4} t^{2}-53,807 P^{2}-97,917 P_{l}^{2}- \\
-43,482 n_{b}+8,042 \cdot 10^{-3} t \cdot P+7,158 \cdot 10^{-3} t \cdot P_{l}+0,012 t \cdot n_{b}+13,64 P \cdot P_{l}+2,016 P \cdot n_{b}-12,439 P_{l} \cdot n_{b} .
\end{gathered}
$$

where $n_{b}$ - bubbling frequency, $\min ^{-1} ; P_{1}$ - bubbling pressure, MPa.

Cottage cheese whey, produced at the enterprise "Kupiansk milk-canning industrial complex" LTD, c. Kupiansk, Kharkiv region, Ukraine, with the following chemical composition: dry substances $-5.4 \%$; protein $1.1 \%$; fat $-0.2 \%$ ).

\section{Results}

At the beginning the influence of bubbling frequency on the productivity of the studied UF-membranes of separated cottage cheese whey at temperature $20{ }^{\circ} \mathrm{C}$ and process pressure $0.4 \mathrm{MPa}[14]$ (Fig. 3) was studied.

Fig. 3 demonstrates that the intensive productivity increase of both membranes takes place at increasing the bubbling frequency to values $0.10 \ldots 0.15 \mathrm{~min}^{-1}$, after which the productivity parameters at membrane concentration of skimmed milk stabilize.

Alongside with the bubbling frequency, the bubbling pressure $\left(P_{1}\right)$ also influences hydrodynamic conditions formation near the surface of semi-penetrable UF-membranes. That is why the influence of the bubbling pressure on the productivity of membranes of PAN type (PAN-50 and PAN-100) was studied at the next stage. The research results are presented on Fig. 4. 
The data of Fig. 4 demonstrate that the bubbling pressure influences the UF process less than the bubbling frequency. With increasing the bubbling pressure, the UF-membranes productivity increases droningly, moreover this dependence is of linear type.

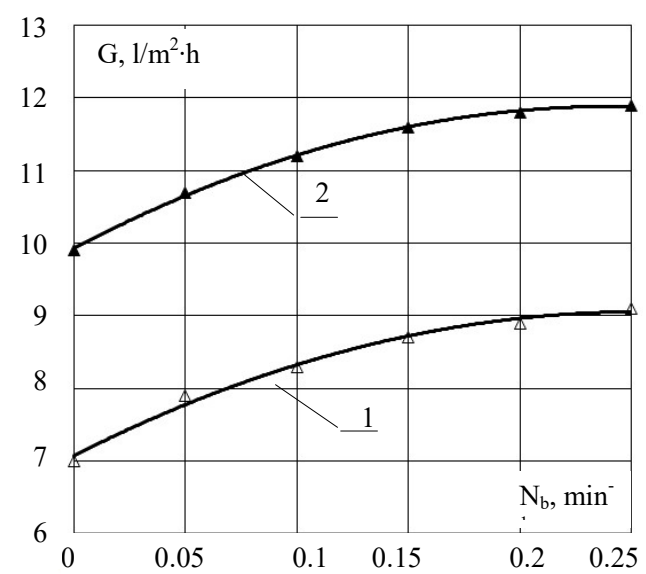

Fig. 3. Dependence of the UF-membranes productivity $(G)$ on the bubbling frequency $\left(n_{b}\right)$ at membrane concentration of cottage cheese whey (temperature $20^{\circ} \mathrm{C}$, filtration pressure $0.4 \mathrm{MPa}$ and bubbling pressure $0.46 \mathrm{MPa}$ ): 1 - membrane PAN-50; 2 - membrane PAN-100

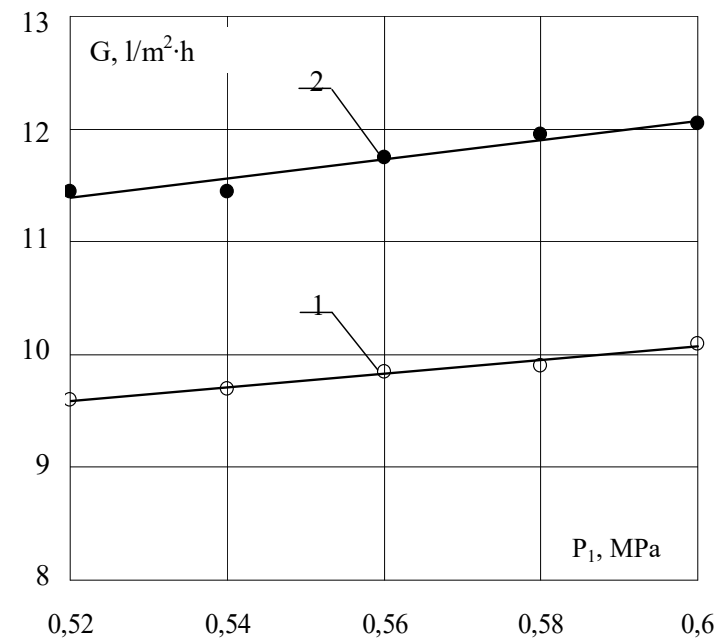

Fig. 4. Dependence of the UF-membranes productivity $(G)$ on the bubbling pressure $\left(n_{b}\right)$ at membrane concentration of cottage cheese whey (temperature $20^{\circ} \mathrm{C}$, filtration pressure $0.4 \mathrm{MPa}$ and bubbling frequency $0.15 \mathrm{~min}^{-1}$ ): 1 - membrane PAN-50; 2 - membrane PAN-100

Optimization of working regimes of the UF process of cottage cheese whey in the blind regime, using the method of polarization layer decrease allowed to construct three-dimensional graphic dependencies (Fig. 5).

The most rational membrane concentration regimes are stressed on the graphic dependences by special shading.

The research results allowed to state that the maximal effectiveness of membrane concentration of cottage cheese whey in the usual regime and also with bubbling is reached at the filtration pressure values $-0.4 \ldots 0.5 \mathrm{MPa}$, temperature $-40 \ldots .50{ }^{\circ} \mathrm{C}$.

Analyzing the results of mathematical modeling, it may be concluded, that at increasing temperature from $20^{\circ} \mathrm{C}$ to $40 \ldots 50{ }^{\circ} \mathrm{C}$ the permeate movement speed increases in $1.29 \ldots 1.32$ times at UF-concentration of skimmed milk at the expanse of its viscosity decrease. But at further temperature increase the speed of UF-concentration almost doesn't change that may be explained by hidden protein coagulation $[15,16]$. 


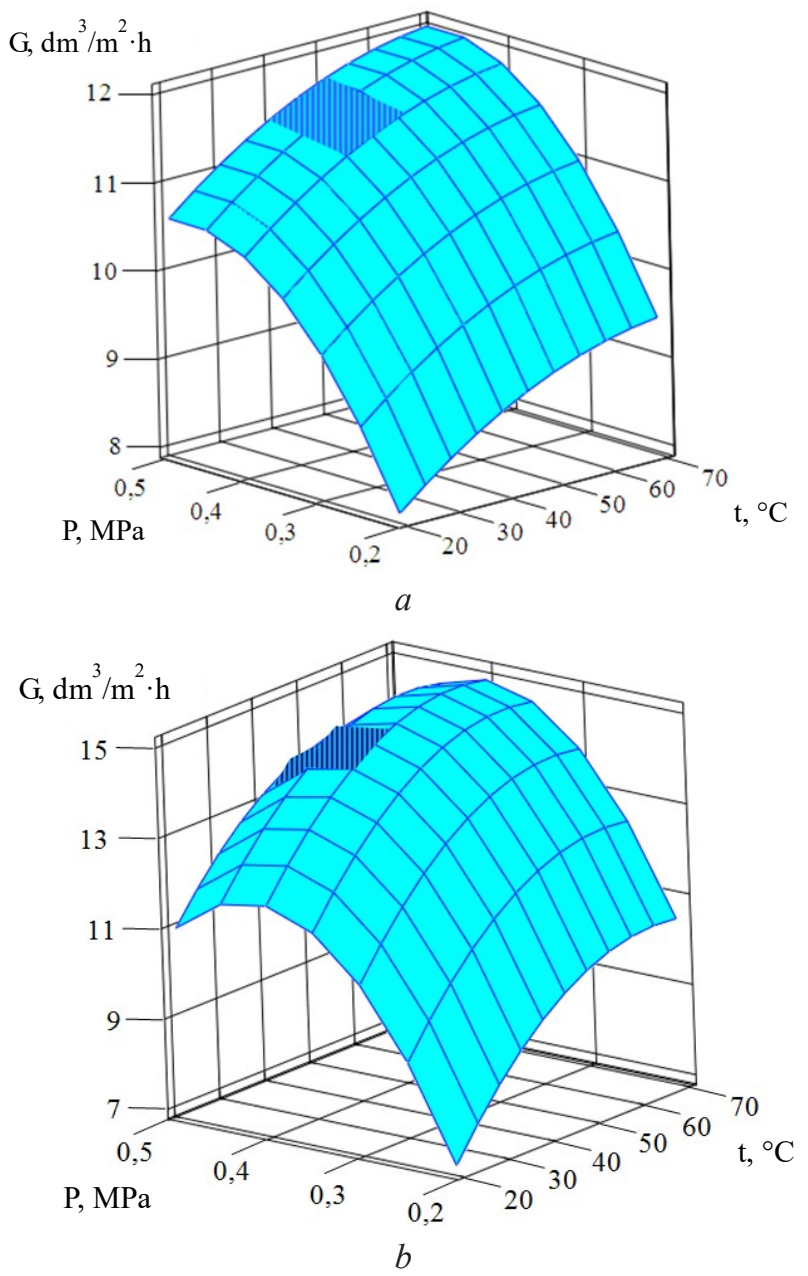

Fig. 5. Mathematical model of choosing working parameters of UF-membranes of PAN type at membrane concentration of cottage cheese whey: $a$ - usual regime; $b$ - with bubbling the raw material at the frequency $n=0.15 \mathrm{~min}^{-1}$ and bubbling pressure $P_{1}=0.58 \mathrm{MPa}$

At increasing pressure of UF process, we can see that the productivity of UF-membranes intensively increases at values $0.3 \ldots 0.4 \mathrm{MPa}$ for the usual regime and $0.4 \ldots 0.5 \mathrm{MPa}$ for using bubbling of the initial raw material, after which the productivity value begins to decrease. Obviously, it is explained by the growth of hydraulic resistance, formed on the residue UF-membrane surface [17].

\section{Conclusions}

The information about the fact that the problem of creating new methods of decreasing the polarization layer on the semi-penetrable membrane surface that would favors the productivity increase of the membrane equipment is urgent today has been obtained.

The experimental results, allowing to determine the rational parameters of the process of membrane concentration of cottage cheese on PAN type membranes using bubbling have been obtained: pressure $-0.4 \ldots 0.5 \mathrm{MPa}$, process temperature $-40 \ldots 50{ }^{\circ} \mathrm{C}$, bubbling frequency $0.10 \ldots 0.15 \mathrm{~min}^{-1}$, bubbling pressure $-0.56 \ldots 0.58 \mathrm{MPa}$.

It has been established, that in the bubbling regime the process of UF-concentration of skimmed milk is intensified, comparing with UF in the blind regime in 1.3..1.4 times. But this phenomenon results only in partial elimination of the polarization layer from the membrane surface.

The conducted studies are the continuation of ones for improving membrane concentration of food liquids using new membranes and ways for decreasing the polarization layer. 
The obtained results may be used at studying other technological parameters of the process of membrane concentration of protein-carbohydrate milk raw materials and also for improving the instrument equipment of lines for processing secondary milk raw materials.

Application of the offered method of membrane concentration of cottage cheese whey allows to raise ecological safety at the expanse of little waste of the process, to increase profitability at the expanse of getting new milk products and to raise the resource-saving component at implementing the method in production.

\section{Refrences}

[1] Babenyshev, S. P., Zhidkov, V. E., Mamay, D. S., Utkin, V. P., Shapakov, N. A. (2016). Ultrafiltration of modified milk whey. Food and Raw Materials, 4 (2), 101-110. doi: https://doi.org/10.21179/2308-4057-2016-2-101-110

[2] Hu, K., Dickson, J. M. (Eds.) (2015). Membrane Processing for Dairy Ingredient Separation. John Wiley \& Sons. doi: https:// doi.org/10.1002/9781118590331

[3] Drioli, E., Giorno, L. (Eds.) (2009). Membrane operations: innovative separations and transformations. Wiley-VCH Verlag GmbH \& Co. KGaA. doi: https://doi.org/10.1002/9783527626779

[4] Bogomolov, V. Yu., Lazarev, S. I. (2014). Promyshlennaya pererabotka vtorichnogo molochnogo syr'ya. Voprosy sovremennoy nauki i praktiki, 1 (50), 82-91.

[5] Kacamarga, M. F., Pardamean, B., Baurley, J. (2014). Comparison of conjugate gradient method and Jacobi method algorithm on MapReduce framework. Applied Mathematical Sciences, 8, 837-849. doi: https://doi.org/10.12988/ams.2014.312698

[6] Lutz, H. (Ed.) (2015). Ultrafiltration for Bioprocessing. United Kingdom: Woodhead Publishing, 244. doi: https://doi.org/ 10.1016/c2013-0-18176-7

[7] Gomaa, H. G., Rao, S. (2011). Analysis of flux enhancement at oscillating flat surface membranes. Journal of Membrane Science, 374 (1-2), 59-66. doi: https://doi.org/10.1016/j.memsci.2011.03.011

[8] Kumar, P., Sharma, N., Ranjan, R., Kumar, S., Bhat, Z. F., Jeong, D. K. (2013). Perspective of Membrane Technology in Dairy Industry: A Review. Asian-Australasian Journal of Animal Sciences, 26 (9), 1347-1358. doi: https:/doi.org/10.5713/ ajas.2013.13082

[9] Cai, M., Zhao, S., Liang, H. (2010). Mechanisms for the enhancement of ultrafiltration and membrane cleaning by different ultrasonic frequencies. Desalination, 263 (1-3), 133-138. doi: https://doi.org/10.1016/j.desal.2010.06.049

[10] Cheng, T.-W., Li, L.-N. (2007). Gas-sparging cross-flow ultrafiltration in flat-plate membrane module: Effects of channel height and membrane inclination. Separation and Purification Technology, 55 (1), 50-55. doi: https://doi.org/10.1016/j.seppur. 2006.10.026

[11] Semenov, A., Lobasenko, B. (2013). Intensification of ultrafiltration concentrating by the separation of the concentration boundary layer. Food and Raw Materials, 1 (1), 74-81. doi: https://doi.org/10.12737/1560

[12] Deynichenko, G., Guzenko, V., Udovenko, O., Omelchenko, A., Melnik, O. (2016). Studying a new anti-polarization method in the process of ultrafiltration of skimmed milk. Eastern-European Journal of Enterprise Technologies, 6 (11 (84)), 4-8. doi: https://doi.org/10.15587/1729-4061.2016.86440

[13] Ostapchuk, M. V., Stankevych, H. M. (2006). Matematychne modeliuvannia na EOM. Odessa: Druk, 313.

[14] Deinychenko, G., Mazniyak, Z., Kramarenko, D., Guzenko, V. (2015). Determination of ultrafiltration membranes shrinkage factor. Ukrainian Food Journal, 4 (2), 328-334. Available at: https://www.researchgate.net/profile/N_Murlykina/publication/295833526_Application_of_infrared_spectroscopy_for_quantitative_analysis_of_new_food_emulsifiers/links/56cdcf9c08ae4d8d6499707c/Application-of-infrared-spectroscopy-for-quantitative-analysis-of-new-food-emulsifiers.pdf\#page=128

[15] Brião, V. B., Tavares, C. R. G. (2012). Pore blocking mechanism for the recovery of milk solids from dairy wastewater by ultrafiltration. Brazilian Journal of Chemical Engineering, 29 (2), 393-407. doi: https://doi.org/10.1590/s0104-66322012000200019

[16] Deynichenko, G., Maznyak, Z., Zolotukhina, I., Gafurov, O. (2011). Membrane concentration of non-fat milk stuff. Industrial Engineering Journal «RECET», 12 (3 (33)), 245-248. Available at: http://www.recentonline.ro/033/Deynichenko_G-2-R33.pdf 